\title{
Kinetics and Mechanism of the Aminolysis of Thiophenyl Cyclopentanecarboxylates in Acetonitrile
}

\author{
Kook Sun Jeong and Hyuck Keun Oh* \\ Department of Chemistry and Research Institute of Physics and Chemistry, Chonbuk National University \\ Choniu 561-756, Korea. "E-mall: ohkeuniáchonbukack" \\ Recerved October 25, 2008, Accepted Vovember 25, 2008
}

Key Wonds: Nucleophilic substitution. Acyl transfer reaction. Cross-interaction constant, Kinetic isotope effects. Stepwise mechanism

The mechanisms of the aminolysis of aryl esters ${ }^{3}$ and carbonates. ${ }^{2}$ and their thiol thiono and dithio derivatives ${ }^{7}$ have been extensively studied. Curved Bronsted plots in the aminolysis reactions have been interpreted in terms of a zwitterionic tetrahedral intermediate. $\mathrm{T}^{-}$. in the reaction path and a change in the rate-limiting step from leaving group expulsion to attack by the nucleophile as the nucleophile becomes more basic. ${ }^{4}$ In some of the cases. however. the aminolysis has been found to proceed concertedly in a single step through a tetrahedral intermediate transition state (TS). ${ }^{+5}$ The mechanistic change from a stepwise through an intermediate. $\mathrm{T}^{-}$, to a concerted via a single TS has been reported to be caused by destabilization of the tetrahedral intermediate, $\mathrm{T}^{-}$, due to several factors. e.g. an enhanced leaving ability of the leaving group (LG). ${ }^{\text {ide }}$ strong electronic push provided by the substrate (nonleaving group) ${ }^{\text {5.b }}$ and destabilization rendered by the amines and by substitution of $\mathrm{S}^{-}$by $\mathrm{O}^{-5 b}$ in the tetrahedral intermediate. $\mathrm{T}^{-}$.

In this work. we investigate the kinetics and mechanism of the aminoly'sis of Z-thiophenyl cyclopentanecarboxylates with $\mathrm{X}$-benzylamines in acetonitrile at $40.0^{\circ} \mathrm{C}$. eq 1 . where $\mathrm{X}=$ $p$-OMe. $p$-Me. H. $p-\mathrm{Cl}$ and $m-\mathrm{Cl}$, and $\mathrm{Z}=p-\mathrm{Me} . \mathrm{H}, p-\mathrm{Cl}$ and $p$-Br.

$$
\begin{aligned}
& {\left[\mathrm{C}-\mathrm{SC}_{6} \mathrm{H}_{4} \mathrm{Z}-2 \mathrm{XC}_{6} \mathrm{H}_{4} \mathrm{CH}_{2} \mathrm{NH}_{2} \frac{\mathrm{MrCN}}{4 \mathrm{COCOC}^{2}}\right.}
\end{aligned}
$$

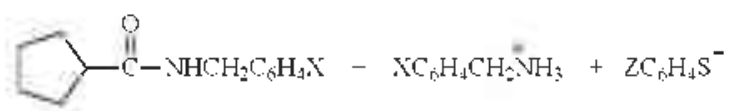

The reactions have been conducted under pseudo-firstorder condition with a large excess of benzylamine. The purpose of this work is to elucidate the mechanism by determining various selectivity parameters. $\rho_{\mathrm{X}}, \beta_{\mathrm{X}} . \rho_{\mathrm{Z}}$ and $\dot{\beta}_{\mathrm{Z}}$. including the cross-interaction constant. ${ }^{6} \rho_{\mathrm{X} Z}$ in eq 2 where $X$ and $Z$ are substituents in the nucleophile and leaving group. respectively. The purpose of the present work is to further expore the effect of the ring acyl group on the aminoly sis mechanism by investigating the structure-reactivity behavior of thiophenyl cyclopentanecar- boxylates in acetonitrile.

$$
\log \left(k_{\mathrm{X} Z} / k_{\mathrm{HH}}\right)=\rho_{\mathrm{X}} \sigma_{\mathrm{X}}+\rho_{\mathrm{Z}}+\rho_{\mathrm{X} Z} \sigma_{\mathrm{X}} \sigma_{\mathrm{Z}}
$$

\section{Results and Discussion}

The aminolysis of thiophenyl cyclopentanecarboxylates with a large excess of benzylamines in acetonitrile obeyed the simple kinetic law given by eqs. (3) and (4), where $\mathrm{P}$ is thiophenolate anion and $\mathrm{N}$ is benzlamine. Plots of $k_{\text {its }}$ against [N] were linear. and the $\mathrm{k}_{\mathrm{N}}$ values were determined in Table 1 . where the $\rho_{\mathrm{x}}, \beta_{\mathrm{K}}\left(\beta_{\mathrm{ulc}}\right), \rho_{\mathrm{Z}}$, and $\beta_{\mathrm{Z}}\left(\beta_{\mathrm{lg}}\right)$ values are also shown.

$$
\begin{aligned}
& d[\mathrm{P}] / d \mathrm{t}=k_{\text {ots }}[\text { substrate }] \\
& k_{\text {cbs }}=k_{1}+k_{2}[\mathrm{~N}]\left(k_{1} \sim 0\right)
\end{aligned}
$$

The clear second-order kinetics obtained, eqs. (3) and (4). is an indication that there are no complications arising from competition of the fast proton transfer from an intermediate $\mathrm{T}^{ \pm}$, nor from general base catalysis by the amines. The mechanism of the reaction can. therefore, be described conpletely by eq. (5). where $\mathrm{Ar}=\mathrm{C}_{6} \mathrm{H}_{4} \mathrm{Z} . \mathrm{XNH}$ represents benzylamines with substituent $X$. The proton transfer can occur during or after the rate-limiting step, $k$. The proton is of course rapidly consumed as $\mathrm{XNH}_{2}{ }^{-}$under the excess amine concentration as shown in eq. (1).

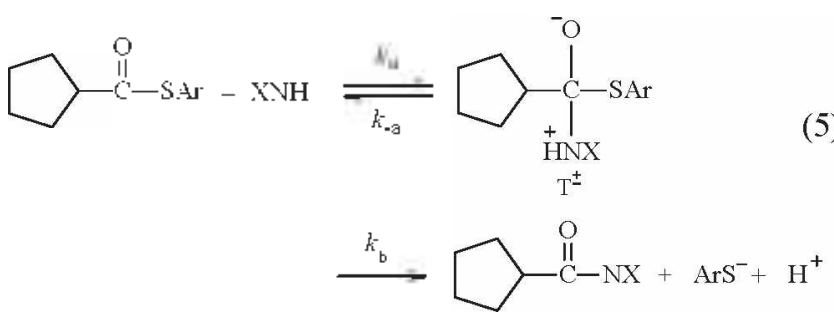

The faster rates of thiophenolates indicate the importance of bond cleavage in the TS. since the thiophenolates used in the present work are weakly basic relative to the phenolates used in the studies and hence are nuch better leaving groups.

Since the reactions were conducted in acetonitrile, the magnitude of $\beta \mathrm{x}\left(\beta_{\mathrm{m} m \mathrm{c}}\right)$ and $\beta_{2}\left(\beta_{\mathrm{lg}}\right)$ deternined using the $\mathrm{p} K_{\mathrm{il}}$ values in water may not be reliable. However. as we have pointed out previously, "the $\beta_{\mathrm{x}}$ values can be considered to represent reliable values, although the absolute values of $\mathrm{p} K_{\mathrm{a}}$ in $\mathrm{MeCN}$ differ from those in water a constant $\Delta \mathrm{pK} K_{\mathrm{a}}\left(\mathrm{p} K_{\mathrm{CH}_{3} \mathrm{CN}}-\mathrm{p} K_{\mathrm{H}_{2} \mathrm{C}}\right) \cong$ $7.7 \pm 0.3$ ) was experimentally found. ${ }^{s}$ Our recent theoretical work of the solvent effect on the basicities of pyridines ${ }^{10}$ has 
Table 1. The Second Order Rate Constants, $\mathrm{k}_{2} \times 10^{3} \mathrm{dm}^{3} \mathrm{mnol}^{-1} \mathrm{~s}^{1}$ for the Reactions of Z-Thiophenyl Cyclopentanecarboxylates with $\mathrm{X}$ Benzylamines in Acetonitrile at $40.0^{\circ} \mathrm{C}$

\begin{tabular}{|c|c|c|c|c|c|c|}
\hline \multirow{2}{*}{$\mathrm{X}$} & \multicolumn{4}{|c|}{$Z$} & \multirow{2}{*}{$\rho z^{a}$} & \multirow{2}{*}{$\beta_{z}^{b}$} \\
\hline & $p^{-\mathrm{Me}}$ & $\mathrm{H}$ & $p \cdot \mathrm{Cl}$ & $p \mathrm{Br}$ & & \\
\hline$p^{-\mathrm{OMe}}$ & $\begin{array}{l}7.98 \pm 0.15 \\
5.58 \pm 0.12^{c} \\
3.84 \pm 0.08^{d}\end{array}$ & $23.0 \pm 0.5$ & $113 \pm 3$ & $\begin{array}{l}135 \pm 4 \\
95.8 \pm 1.5^{\prime} \\
67.1 \pm 0.8^{i}\end{array}$ & $3.01 \pm 0.12$ & $-1.24 \pm 0.07$ \\
\hline$p-\mathrm{Me}$ & $4.87 \pm 0.08$ & $16.3 \pm 0.2$ & $79.2 \pm 1.2$ & $99.8 \pm 1.8$ & $3.17 \pm 0.13$ & $-1.29 \pm 0.13$ \\
\hline $\mathrm{H}$ & $1.92 \pm 0.05$ & $7.14 \pm 0.08$ & $41.0 \pm 0.3$ & $53.7 \pm 0.6$ & $3.49 \pm 0.15$ & $-1.42 \pm 0.13$ \\
\hline$p \mathrm{Cl}$ & $\begin{array}{l}0.620 \pm 0.005 \\
0.427 \pm 0.003^{\circ} \\
0.303 \pm 0.002^{c}\end{array}$ & $2.61 \pm 0.05$ & $19.6 \pm 0.2$ & $\begin{array}{l}26.0 \pm 0.4 \\
18.4 \pm 0.2^{c} \\
12.6 \pm 0.1^{d}\end{array}$ & $3.94 \pm 0.17$ & $-1.61 \pm 0.12$ \\
\hline$n-\mathrm{Cl}$ & $0.300 \pm 0.002$ & $1.34 \pm 0.03$ & $10.7 \pm 0.1$ & $14.4 \pm 0.2$ & $4.07 \pm 0.17$ & $-1.66 \pm 0.13$ \\
\hline$\rho \mathrm{x}^{a}$ & $-2.23 \pm 0.02$ & $-1.95 \pm 0.03$ & $-1.58 \pm 0.03$ & $-1.51 \pm 0.03$ & $\rho_{x z}{ }^{c}=$ & $1.72 \pm 0.04$ \\
\hline$\beta_{x}^{\prime}$ & $2.25 \pm 0.04$ & $1.97 \pm 0.05$ & $1.59 \pm 0.05$ & $1.52 \pm 0.05$ & & \\
\hline
\end{tabular}

"The $\sigma$ values were taken from Hansch, C.: Leo, A.: Taft. R. W. Chem. Rev. 1991. 91. 166. Correlation coefficients were better than 0.998 in all cases. "The $\mathrm{pKa}$ values were taken from ed. Bukingham. J. Dictionav of Organic Chemistry. Chapman and Hall. New York, 1982, 5th. ed. Z = m-Me was excluded from the Brōnsted plot for $\beta_{z}$ due to an unreliable pKa values. Correlation coefticients were better than 0.996 in all cases. ${ }^{\circ} \mathrm{At} 30^{\circ} \mathrm{C}$. ${ }^{d} \mathrm{At} 20^{\circ} \mathrm{C}$. 'Correlation coefficients was 0.998. 'The pKa values were taken fron Fischer, A.: Glloway. W. I.; Vanghan, J. J. Chem. Soc. 1964. 3588. Correlation coefficients were better than 0.998 in all cases. $\mathrm{pK}_{\mathrm{a}}=9.64$ was used for $\mathrm{X}=p-\mathrm{CH}_{3} \mathrm{O}$. (reference Oh. H. K.: Lee. J. Y.: Lee, I. Bull Korean Chem. Soc. 1998. 19. 1198$)$

shown that the $\Delta \mathrm{pK}_{\mathrm{a}}(\cong 7.7)$ value arises solely from the ion salvation energy difference of $\mathrm{H}^{-}$ion in water and acetonitrile. $\hat{\delta} \Delta G_{\mathrm{s}}{ }^{\circ}\left(\mathrm{H}^{-}\right)=10.5 \mathrm{kcal} \mathrm{mol}^{\cdot]}$. which corresponds to $\Delta \mathrm{p} K_{\mathrm{a}}=$ 7.7 , at the MP2/6-31G*//MP2/6-31G* level ${ }^{1 \mathrm{l}}$ of theory. Moreover. we are comparing the magnitude of $\beta_{x}$ and $\beta_{Z}$ determinied for the reactions carried out under the same reaction condition (i.e.. in acetonitrile). Since we used $\mathrm{p} K_{\mathrm{a}}$ values of thiophenolates in water, the camparison of $\beta_{Z}$ values may not be entirely reliable.

We note that the magnitude of $\beta \mathrm{x}$ in Table $1(\beta=1.52 \sim$ 2.25 ) is considerably larger than those for the corresponding reactions with anilines and other secondary and tertiary amines $\left(\beta_{\mathrm{X}}=0.6 \sim 1.0\right)^{12}$ proceeding by rate-limiting breakdown $\left(h_{b}\right)$ of a zwitter-ionic tetrahedral intennediate. $\mathrm{T}^{=}$. eq. (5). On this account (i.e. large $\beta_{\mathrm{X}}$ values). the aminoly sis of thiophenyl cyclopentanecarboxylates with benzylamines in acetonitrile, eq. (1). is most likely to occur by rate-limiting expulsion. $k_{\mathrm{b}}$. in eq. (5), of thiophenolate ion, $\mathrm{ArS}$. from $\mathrm{T}^{=}$.

The magnitude of $\beta_{\mathrm{X}}$ in Table $1\left(\beta_{\mathrm{X}}=1.52-2.25\right)$ is again much larger than those for the corresponding reactions with anilines and other secondary and tertiary amines $\left(\beta_{\mathrm{X}}=0.6\right.$ $1.0)^{12}$ but similar to those with benzylamines $\left(\beta_{X}=1.4-2.5\right)$. All of these latter values are for the thiol ester aminoly sis with benzylamines in acetonitrile which are predicted to proceeded by rate-limiting breakdown of a zwitterionic tetrahedral intermediate $\mathrm{T}^{ \pm}$. On this account. i.e. large $\beta_{\mathrm{X}}$ values obtained the aminolysis of thiophenyl cyclopentane- carboxylate with benzylamines in acetonitrile is most likely to occur by the rate-limiting expulsion of thiophenolate ion $\mathrm{ArS}^{-}$, from $\mathrm{T}^{=}$. eq. (5), where the proton is consumed by the excess benzylamine present in the solution in a subsequent rapid step to form benzylammonium ion. The rate constant. $k_{2}$ in eq. 3 , is therefore a complex quantity represented by eq. 6 . The magnitude of $\beta_{Z}\left(\beta_{18}\right)$ values $\left(\beta_{Z}=-1.24 \sim-1.66\right.$ ) is also comparable to or greater than that for the similar reaction with rate-limiting expulsion of ArS $^{*}$ in acetonitrile $\left(\beta_{Z}=-1.2 \sim-1.5\right)^{13}$

$$
k_{2}=\frac{k_{a}}{k} \cdot k_{b}=K \cdot k_{b}
$$

The proposed mechanism is also supported by a large positive cross-interaction constant $\left(\rho_{\mathrm{xz}}=1.72\right)$ and adherence to the reactivity-selectivity principle (RSP), which are considered to constitute necessary conditions for the rate-limiting breakdown of $\mathrm{T}^{ \pm}{ }^{14}$

The kinetic isotope effects $\left(k_{\mathrm{H}} / k_{\mathrm{D}}\right)$ in Table 2 imvolving deuterated benzylamine $\left(\mathrm{XC}_{6} \mathrm{H}_{4} \mathrm{CH}_{2} \mathrm{ND}_{2}\right)$ nucleophiles in acetonitrile are greater than unity $\left(k_{\mathrm{H}} / k_{\mathrm{D}}=1.4 \sim 1.6\right)$, indicating that the $\mathrm{N}-\mathrm{H}$ proton transfer takes place in the rate determining step ${ }^{15}$ so that a four-center type TS is involved. ${ }^{15}$ In this type of TS. hydrogen bonding of an amine hydrogen atom to the de-

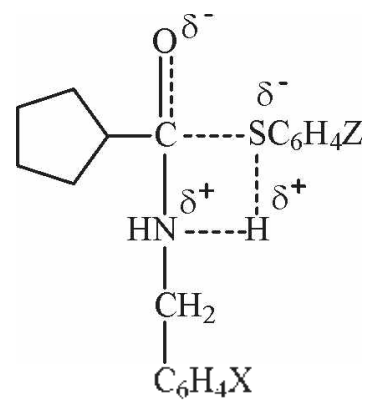

Proposed TS 
Table 2. Kinetic Isotope Effects for the Reactions of Z-Thiophenyl Cyclopentanecarbosylates with Deuterated X-Benzylamines in Acetonitrile at $40.0^{\circ} \mathrm{C}$

\begin{tabular}{ccccc}
\hline $\mathrm{X}$ & $\mathrm{Z}$ & $k_{\mathrm{H}} \times 10^{3}\left(\mathrm{M}^{-1} \mathrm{~s}^{-1}\right)$ & $k_{\mathrm{D}} \times 10^{3}\left(\mathrm{M}^{1} \mathrm{~s}^{-1}\right)$ & $k_{\mathrm{H}} / k_{\mathrm{I}}$ \\
\hline$p-\mathrm{OMe}$ & $p-\mathrm{Me}$ & $7.98 \pm 0.15^{\sigma}$ & $5.14 \pm 0.06$ & $1.55 \pm 0.02^{b}$ \\
$p-\mathrm{OMe}$ & $\mathrm{H}$ & $23.0 \pm 0.5$ & $15.4 \pm 0.3$ & $1.49 \pm 0.02$ \\
$p-\mathrm{Me}$ & $p-\mathrm{Cl}$ & $113 \pm 3$ & $79.0 \pm 1.8$ & $1.43 \pm 0.03$ \\
$p-\mathrm{OMe}$ & $p-\mathrm{Br}$ & $135 \pm 4$ & $97.8 \pm 2.2$ & $1.38 \pm 0.03$ \\
$p-\mathrm{Cl}$ & $p-\mathrm{Me}$ & $0.620 \pm 0.005$ & $0.392 \pm 0.003$ & $1.58 \pm 0.04$ \\
$p-\mathrm{Cl}$ & $\mathrm{H}$ & $2.61 \pm 0.05$ & $1.71 \pm 0.02$ & $1.53 \pm 0.02$ \\
$p-\mathrm{Cl}$ & $p-\mathrm{Cl}$ & $19.6 \pm 0.2$ & $13.4 \pm 0.2$ & $1.46 \pm 0.02$ \\
$p-\mathrm{Cl}$ & $p-\mathrm{Br}$ & $26.0 \pm 0.4$ & $18.5 \pm 0.2$ & $1.40 \pm 0.03$ \\
\hline
\end{tabular}

${ }^{\sigma}$ Standard deviations. ${ }^{b}$ Standard errors.

Table 3. Activation Paraneters for the Reactions of Z-Thiophenyl Cyclopentanecarboxylates with X-Benzy lannines in Acetonitrile

\begin{tabular}{llcc}
\hline \multicolumn{1}{c}{$\mathrm{X}$} & \multicolumn{1}{c}{2} & $H^{=} / \mathrm{kcal} \mathrm{mol}^{-1}$ & $-\Delta \mathrm{S}^{-} / \mathrm{cal} \mathrm{mol}^{-1} \mathrm{~K}^{-1}$ \\
\hline$p-\mathrm{OMe}$ & $p-\mathrm{Me}$ & 6.0 & 48 \\
$p-\mathrm{OMe}$ & $p-\mathrm{Br}$ & 5.8 & 44 \\
$p-\mathrm{Cl}$ & $p-\mathrm{Me}$ & 5.8 & 55 \\
$p-\mathrm{Cl}$ & $p-\mathrm{Br}$ & 5.8 & 47 \\
\hline
\end{tabular}

"Calculated by the Evring equation. The maximum errors calculated (by the method of Wiberg. K. B. Plnsical Orgaric Chemistrv. Wiley: New York,

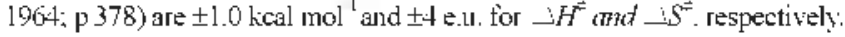

parting thiophenoxide facilitates the rate-limiting bond cleavage step. forming a rather constrained four membered ring.

The low activation enthalpies. $\Delta H^{=}$. and highly negative activation entropies. $\Delta S^{=}$, (Table 3 ) are also in line with the proposed TS. Especially. the $\Delta H^{=}$values are somewhat lower and the $\Delta S^{=}$values are higher negative values than other aminolysis systems. ${ }^{14}$ The expulsion of RS' anion in the rate determining step (an endoergic process) is assisted by the hy'drogen-bonding with an amino hydrogen of the benzylammonium ion within the internediate. $\mathrm{T}^{ \pm}$. This will lower the $\Delta H^{=}$value, but the TS becomes structured and rigid (low entropy process) which should lead to a large negative $\Delta S^{=}$ value.

In sumunary the aminolysis of thiophenyl cyclopentanecarboxylates with benzy lamines in acetonitrile proceeds by rate-limiting breakdown of a tetrahedral intermediate. $\mathrm{T}^{\dot{x}}$. The unusually large $\beta_{N}\left(\beta_{\text {ni: }}\right)$ values can be accounted for by a strong localized cationic charge on the nitrogen atom of benzylamines in $\mathrm{T}^{ \pm}$. which is lost in the benzylamine expulsion from $\mathrm{T}^{=}\left(k_{a}\right)$. The breakdown rate ratio of $k_{\cdot \sigma} k_{b}$ is large due to large $k_{-\alpha}$ and relatively small $k_{\text {b. }}$. The proposed mechanism is also supported by a large positive cross-interaction constant. $\rho_{\mathrm{Xz}}$ $(=1.72)$. adherence to the RSP, and low activation parameters. The greater than unity $k_{H} k_{D}$ values involving deuterated benzylamines suggests a four-center type hydrogen-bonded TS

\section{Experimental Section}

Materials. Aacetonitrile (Merk G R) was used after threetime distillations. The benzylamine nucleophiles (Aldrich GR) were used without further purification.
Substrates. Preparations and analỵtical data are reported elsewhere. $^{16}$

Kinetic Measurement. Rates were measured conductometrically at $40.0 \pm 0.05^{\circ} \mathrm{C}$. The conductivity bridge used in this work was a self-made conputer automatic $\mathrm{A} / \mathrm{D}$ converter conductivity bridge. Pseudo-first-order rate constants. $k_{\text {cbs. }}$

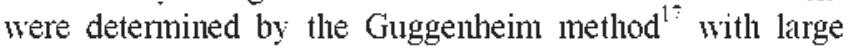
excess of benzylanine. Second-order rate constants. $k_{z}$. were obtained from the slope of a plot of $k_{\mathrm{cbs}} \mathrm{w}$. [benzylamine] with more than five concentrations of benzylanine eq. 4 . The $k_{2}$ values in Table $\mathrm{I}$ are averges of more than three nuns and were reproducible to within $\pm 3 \%$.

Product Analysis. Substrate ( $0.05 \mathrm{~mole}$ ) and benzylamine $\left(0.5\right.$ mole) were added to acetonitrile and reacted $40.0^{\circ} \mathrm{C}$ under the same condition as the kinetic measurements. After more than 15 half lives. solvent was removed under reduced pressure and product was separated by column chromatography (silica gel. $10 \%$ ethylacetate-n-hexane). Analy'sis of the product gave the following results

Cyclopentyl-C $(=\mathbf{0}) \mathbf{N H C H}_{2} \mathbf{C}_{6} \mathbf{H}_{4}-\mathbf{O C H}_{3}:$ m.p. $192 \sim 194^{\circ} \mathrm{C}$. IR(KBr), 3251(N-H), 3010(C-H, benzyl), 2936(C-H, $\left.\mathrm{CH}_{2}\right)$, $2943\left(\mathrm{C}-\mathrm{H} . \mathrm{CH}_{3}\right), 1634(\mathrm{C}=\mathrm{O}) .1534(\mathrm{C}=\mathrm{C}$, aromatic $), 1262$, 1035(C-O): ${ }^{1} \mathrm{H} \mathrm{NMR}\left(400 \mathrm{MHz}, \mathrm{CDCl}_{3}\right), 1.12 \sim 1.17(8 \mathrm{H}, \mathrm{m}$, $\left.\mathrm{CH}_{2}\right), 1.55-1.66(1 \mathrm{H}, \mathrm{m} . \mathrm{CH}), 3.69\left(3 \mathrm{H}, \mathrm{s}, \mathrm{CH}_{3}\right) .4 .25(2 \mathrm{H} . \mathrm{d}$, $\left.\mathrm{CH}_{2}\right) .7 .08(2 \mathrm{H}$. d. $J=8.78 \mathrm{MHz}$. meta H). $7.29(2 \mathrm{H}$, d. $J=8.30$ $\mathrm{MHz}$, ortho $\mathrm{H}):{ }^{13} \mathrm{C} \mathrm{NMR}\left(100.4 \mathrm{MHz}, \mathrm{CDCl}_{3}\right) .176 .3(\mathrm{C}=\mathrm{O})$, $158.7,129.1,128.9,113.8,63.7,45.6 .42 .8,30.9 .25 .7 .:$ Mass. $m: 233\left(\mathrm{M}^{+}\right)$. Anal. Calcd for $\mathrm{C}_{1} \mathrm{H}_{19} \mathrm{NO}_{2}$ : C. 72.1 : H. 8.21 . Found: C. $72.3 ;$ H. 8.19.

Aclonowledgments. This paper was supported by research fund of Chonbuk National University.

\section{References}

1. (a) Satterthwait, A. C. Tencks, W. P. J. Am Chem Soc. 1974, 96 , 7018. (b) Johnson, S. L. Adv Phy Ong Chem 1967, 5, 237. (c) O'Leary, M. H.; Marlier, J. F. J. Am. Chem. Soc. 1979,101, 3300. (d) Koh, H. T; Lee, H. C.; Lee, H. W.; Lee, I. Bull Korean Chem. Soc. 1995, 16, 839. (e) Castro, E. A.; Steinfort, G. B. J. Chem. Soc, Perhin Trans. 2 1983,453. (f) Palling. D. J.: Jencks, W. P. J. 4m. Chem. Soc. 1984, 106, 4869 (g) Castro, E. A.: Santander. C. L. J. Org. Chem. 1985, 50, 3595. (h) Castro, E. A; Ureta, C. $J$. Org. Chem. 1990, 55, 1676. (j) Koh, H. T.; Shin, C. H.; Lee, H. 
W.: Lee, I. J. Chem. Soc., Perkin Trans. 2 1998, 1329.

2. (a) Gresser, M. I.; Jencks, W. P. J. Am Chem Soc. 1977, 99 , 6963, 6970. (b) Bond, P. M. Moodie, R. B. J. Chem. Soc. Pertin Trans. 2 1976, 679 (c) Castro, E. A.; Gil, F. J. J. Ant. Chent. Soc. 1977, 99,7611. (d) Castro. E. A.: Freudenberg, M. J. Org. Chem. $1980,45,906$. (e) Castro, E. A.: Ibanez, F.: Lagos, S.; Schick, M.: Santos, T. G. J. Org (Them. 1992, 57, 2691 (f) Castro, E. A.: Ibanez, F. ; Saitua, A. M.: Santos, J. G. J. Chent. Res. Synop. $1993,56$.

3. Castro, E. A. Chem Rev 1999, 99, 3505.

4. Willians, A. Concerted Onganic and Bio-organic Mechanisms; CRC Press: Boca Raton, 2000: Chapter 4.

5. (a) Castro, E. A.; Ibanez, F.; Salas, M.; Santos, J. G. J. Org. Chem. 1991, 56, 4819. (b) Castro, E. A.; Salas, M.; Santos, T. G. J. Org. Chem. 1994. 59. 30. (c) Oh. H. K.: Shin, C. H.: Lee. I. Bull Korean Chem. Soc 1995, 16, 657. (d) Castro, E. A.: Munoz, P.; Santos, J. G. J. Org. Chent 1999, 6t, 8298. (e) Castro, E. A. Leandro, L.; Millan, P.: Santos, T. G. J. Org. Chem. 1999. 64. 1953. (f) Skoog. M. T. Iencks. W. P. J. Am. Chem. Soc. 1984, 106, 7597. (g) Boume, N.; Williams, A. J. Am Chem. Soc. 1984, 106, 7591. (h) Ba-Saif, S. A.; Luthra, A. K.; Williams, A. J. Ant. Chem. Soc. $1989,111,2647$.

6. (a) Lee, I. Adw Phws Org. Chem 1992, 27, 57 (b) Lee, I. Chem. Soc. Rev 1994, 24, 223. (c) Lee. I.: Lee. H. W. Coll Czech. Chem Commm. 1999, 64, 1529. (d) Oh, H. K.; Lee, T. Y.: Lee, H. W.; Lee, I. Jew J. Chem. 2002, 26,473, (e) Teong, K. S. Oh,
H. K. Bull. Koreon Chem. Soc. 2007, $28,2535$.

7. Oh, H. K, Woo, S. Y.: Shin, C. H.; Park, Y. S.: Lee, I. J. Org. Chem. 1997, 62,5780

8. Koh, H. I.; Lee, J. W; Lee, H W; Le, I. Can. J. Chen 1988, $76,710$.

9. The average $\Delta p K_{\mathrm{a}}$ of $7.7 \pm 0.3$ was obtained from $22 \mathrm{p} K_{\mathrm{a}}$ values for alkyl and alicyclic amines reported in Coetzee, T. F. Prog. Phs. Org. Chem 1967, 4,454.

10. Lee, I.; Kim, C. K.: Han, I. S.; Kim, W. K.: Kim, Y. B. J. Phws. Chem. $B$ 1999, 103, 7302.

11. Hehre, W. J.; Radom, L.; Schlever, P. V. R.; Pople, J. A. In $a b$ initio M lelecula Orbital Theon. Wiley: New York, 1986. Chapter 4.

12. Yew, K. H.: Koh. H. I.: Lee. H. W.: Lee, I. J. Chem. Soc. Pertim Trans. 21995,2263

13. Lee, H. W: Yun, Y. S.; Lee, B. S.; Koh, H. T.; Lee, I. J. Chent. Soc. Perkin Trans. 22000,2302

14. (a) Koh, H. J.: Han. K. L.: Lee. I. J. Ong. Chem. 1999. 64. 4783 (b) Koh, H. J.; Kim, S. I.; Lee, B. C.; Lee, I. J. Chem Soc. Pertim Trans. 2 1996, 1353 . (c) Lee, I. Kol, H. T. New J. Chem 1996, 20, 132. (d) Oh, H. K.; Woo, S. Y.; Shin, C. H.; Park, Y. S.; Lee, I. J. Ong Chem 1997, 62, 5780. (e) Oh. H. K.: Jeong. I. Bull. Korean Chem. Soc. 2001, 22, 1123

15. Pross, A. Adv. Phws. Org. Chem. 1997, 14,69.

16. Teong, K. S.; Oh, H. K. Bull. Kowan Chem. Soc. 2008, $29,675$.

17. (a) Guggenheim, E. A. Phil Mag 1926, 2, 538 (b) Jeong. K. S.: Oh, H. K. Bull Korean Chem. Soc. 2007, 28, 485. (c) Oh, H. K; Oh. I. Y. Bull. Korean Chem. Soc. 2006. 27. 143. 